\title{
El Símbolo como Limitación y Tránsito en el sistema Kantiano
}

\author{
Ulises Salomón Amaya Pérez ${ }^{1}$ \\ Recibido en mayo de 2016, aceptado en julio de 2016
}

No se trata de traspasar el límite, sino de habitarlo.

Felipe Kong

\begin{abstract}
Resumen
La intención de este artículo es realizar una aproximación a la lectura hermenéutica de la obra kantiana propuesta por Mario Caimi para quien el símbolo estaría a la base de su planteamiento metafísico. Iniciaremos señalando el carácter interpretativo propio del ser humano desde categorías heideggerianas y que está a la base de la capacidad simbólica que posee para en un segundo momento realizar una sucinta explicación de cómo funciona la analogía en el proceso de la hipotiposis simbólica ${ }^{2}$ finalizando con una pequeña aproxi-mación al carácter de limitación que el símbolo posee y que es fundamental, según Caimi, en el desarrollo de la metafísica kantiana.
\end{abstract}

\section{Palabras claves}

Comprender, interpretación, símbolo, analogía, limitación, límite, tránsito.

\begin{abstract}
The purpose of this article is to approach the hermeneutic reading of Kantian work proposed by Mario Caimi, for whom symbolism is the base of his metaphysical approach. We will begin by pointing out the unique interpretive character of humans and that this is at the base of the capacity for symbolism that they posess. Subsequently, we will create a succinct explanation of how analogies work in the process of the symbolic hypothesis. We will end with an approach to the character of limitation that the symbol possesses, and that, according to Caimi, is fundamental in the development of Kantian metaphysics.
\end{abstract}

\section{Keywords}

Understand, interpretation, symbol, analogy, limitation, limit, crossing.

1. Licenciado en Filosofía por la Universidad Centroamericana "José Simeón Cañas", San Salvador, El Salvador, Centroamérica. Dr. en Filosofía por la Pontificia Universidad Católica de Valparaíso, Chile. Becario PUCV. E-mail: oddysseus.abaddon@gmail.com

2. Debemos enfatizar que la intención de este trabajo no es la explicación de la hipotiposis simbólica, por lo que nos detendremos sólo en lo que sea importante, desde nuestra perspectiva, para la consecución de nuestro objetivo. 


\section{Introducción}

Se podría pensar que la pretensión del pensamiento crítico kantiano gira solamente en torno a la posibilidad epistemológica de la experiencia, es decir, a la forma en que el conocimiento se encuentra estrechamente vinculado a la forma en que los objetos acontecen ante él, sin embargo, al leer con atención a Kant se nos devela una intención que al menos, en principio, parecería contradictoria a lo que nuestro autor habría señalado en la primera crítica. Kant pretende solucionar los problemas tradicionales planteados en la metafísica, sobre todo en Leibniz y Wolff. ${ }^{3}$ Esta pretensión se vuelve una empresa complicada puesto que el pretender solucionar los problemas planteados en el despliegue metafísico implica adentrarse en un terreno que anteriormente había sido excluido por nuestro autor y, es más, del que habría negado la posibilidad de obtener cualquier tipo de conocimiento, nos referimos al terreno de lo suprasensible, el noúmeno.

Kant, nos parece, comprende la metafísica como algo que no puede ubicarse solamente en el terreno de la razón práctica, pero tampoco en el terreno de lo meramente teórico, más bien, la metafísica sería un terreno de tránsito4, un tránsito de lo sensible a lo suprasensible, o, en lenguaje más kantiano, de lo fenoménico a lo nouménico. Sin embargo, ante esta afirmación pronto nos sale al paso la siguiente interrogante ¿De qué manera nos podemos dar cuenta de un objeto o una realidad más allá de lo fenoménico cuando nuestro lenguaje está enclaustrado en lo empírico?, ${ }^{5}$ en otras palabras, en Kant, para que haya conocimiento, ¿no puede darse un concepto independiente de la intuición, es decir, de la experiencia, así, al pretender dar cuenta de objetos supraempíricos no estaremos entrando a un terreno clausurado por el mismo Kant?

Ciertamente, Kant ha excluido la posibilidad del conocimiento de lo nouménico en la primera crítica, sin embargo, en la tercera critica, nos parece, deja abierta la posibilidad de dar cuenta de aquello a través de una de las posibilidades que nuestro lenguaje, o más bien, nuestra facultad comunicativa, posee, a saber, el símbolo. Dicho esto, el presente trabajo pretende hacer un pequeño acercamiento a la relación existente entre el símbolo y la comprensión kantiana de la metafísica.

\footnotetext{
3.Veáse, Caimi, Mario, La metafisica de Kant. Reconstrucción de la argumentación del escrito de Kant "Los progresos de la metafísica desde la época de Leibniz y de Wolff", Editorial Universitaria de Buenos Aires, Buenos aires, 1989.

4. Cfr., Caimi, Mario, Op.cit., p.23.

5.Véase, Piepper, Annemarie, Kant und die Methode der Analogie, en Kant in der diskussion der Moderne, hrg. Von G. Schönrich und Yasushi Kato, Frankfurt, 1997.
} 


\section{El carácter interpretativo del ser humano y su relación con lo simbólico}

El ser humano habita el mundo como una realidad abierta y no cerrada como el resto de animales, ${ }^{6}$ se encuentra en aperturidad (Erschlossenheit) ante el mundo (Welt) y esa aperturidad (Erschlossenheit) se manifiesta como un comprender (Verstehen). En este sentido Heidegger nos dice en Sein und Zeit, "La apertura del comprender concierne siempre a la constitución fundamental entera del estar-en-el-mundo"; ${ }^{7}$ el comprender (Verstehen) es así una nota constitutiva del ser humano, pero ese comprender (Verstehen) posee una nota característica, es un comprender que interpreta. En este sentido Heidegger nos dice, también en Sein und Zeit:

"El proyectarse del comprender tiene su propia posibilidad de desarrollo. A este desarrollo del comprender lo llamamos interpretación. En la interpretación el comprender se apropia comprensoramente de lo comprendido por él. En la interpretación el comprender no se convierte en otra cosa, sino que llega a ser él mismo. La interpretación se funda existencialmente en el comprender, y no es éste el que llega a ser por medio de aquella". ${ }^{8}$

El ser humano entonces habita en la interpretación (Auslegung) y su habérselas con el mundo es un habérselas interpretativo. Este carácter interpretativo, nos parece, se debe, no sólo a una nota constitutiva del ser humano, sino también a su afán explicativo y de dotar de sentido el mundo en el que se encuentra, Heidegger nos dice en Sein und Zeit:

"En la medida en que el comprender y la interpretación conforman la constitución existencial del ser del Ahí, el sentido debe ser concebido como la estructura existencial-formal de la aperturidad que es propia del comprender. El sentido es un existencial del Dasein y no una propiedad que adhiera al ente, que esté "detrás" de él o que se cierna en alguna parte como "región intermedia"."

6. Cfr., Domínguez Miranda, Manuel, Aproximaciones al concepto de praxis en Ignacio Ellacuría, en, Universitas Philosophica 21, Bogotá, 1993, p. 49

7. Heidegger, Martin, Ser y Tiempo, Trotta, Madrid, 2003, p. 148, § 31. "Das Verstehen betrifft als ErschlieBen immer die ganze Grundverfassung des In-der-Welt-seins”.

8. Ibid., p. 151, § 32. “Das Entwerten des Verstehen hat die eigene Möglichkeit, sich auszubilden. Die Ausbildung des Verstehens nennen Wir Auslegung. In ihr eignet sich das Verstehen sein Verstandenes verstehend zu. In der Auslegung wird das Verstehen nicht etwas anderes, sondern es selbst. Auslegung gründet existenzial im Verstehen, und nicht entsteht dieses durch jene".

9. Ibid., p. 154, § 32. "Sofern Verstehen und Auslegung die existenziale Verfassung das Sein des Da ausmachen, muB Sinn las da formal-existenziale Gerüst der dem Verstehen zugehörigen Erschlossenheit begriffen werdem. Sinn ist ein Existenzial des Dasein, nicht eine Eigenschaft, die am Seiende haftet "hinter" ihm liegt oder als "Zwischenreich" irgendwo shwebt". 
Ese dotar de sentido y significación la realidad se realiza a través del lenguaje, éste también manifiesta el carácter de aperturidad (Erschlossenheit) del ser humano. Al nombrar las cosas éstas comparecen ante él, y al nombrarlas se suscita su existencia; sólo así, a través del lenguaje, las cosas pueden existir como tales, por ello, éstas sólo son cosas para un sujeto que las nombra. "Sin el lenguaje las cosas no serían nunca eso que son, pues es él quien las suscita y nos da el poder de suscitarlas". ${ }^{10}$

Es clara la estrecha relación entre el comprender o pensar y el lenguaje. Ahora bien, si las cosas, o realidades, comparecen sólo al ser nombradas qué sucede con cierto tipo de realidades que son irreductibles a la operación conceptual ${ }^{11}$, es decir, con aquellas que resisten al enclaustramiento que el concepto implica y que señalan la imposibilidad de la pretensión cartesiana de llegar a un estadio "meramente conceptual", ${ }^{12}$ este cuestionamiento nos lleva a las posibilidades que el mismo lenguaje, o más bien, que esa capacidad de comunicarnos, de lo cual el lenguaje es su manifestación, nos brinda y que escapa de ese carácter de enclaustramiento del concepto, a saber, los símbolos.

En este trabajo nos interesa un tipo particular de símbolo que aparece recurrentemente en la obra kantiana pero que es desarrollado en la $\mathrm{KU}$ a saber, la metáfora, no entraremos en la discusión sobre si es un símbolo o no, y si lo es cuál sería su diferencia con otros tipos de símbolos, partiremos, más bien, de la asunción de que es una manifestación simbólica más y que su diferencia radical, desde nuestra perspectiva, radica en que se manifiesta en el habla, y debido a ello nos permite expresar ciertas realidades inconceptualizables, y así nos permite trascender la limitación empírica que condiciona nuestro lenguaje, a pesar de ello, el periplo de la metáfora ha sido difícil y se le ha negado su aporte al proceso de comprensión en el despliegue del pensamiento filosófico, con el mal llamado paso del mito al $\operatorname{logos}^{13}$ la metáfora quedó relegada a la marginalidad de la filosofía y pensada como una mera figura retórica debido, nos parece, al carácter abierto de ésta, la metáfora no enclaustra, no define, sólo sugiere, es un hablar sugerente ${ }^{14}$ y precisamente por ello posee la capacidad de aproximarse a aquello que se resiste al enclaustramiento del logos y eso que presenta resistencias son las realidades supraempíricas.

10. Corvez, Maurice, La Filosofía de Heidegger, Fondo de Cultura económica, México, D.F., 1970. p. 47.

11. Véase, Blumenberg, Hans, Paradigmas para una metaforología, Trotta, Madrid, 2003

12. Cfr., Rivera, Antonio, Hans Blumenberg: mito, metáfora absoluta y filosofía política. En: INGENIUM Revista de Historia del Pensamiento Moderno, № 4, julio-diciembre 2010: 145-165

13. "Mal llamado paso del mito al logos" porque no se trata de un paso, verlo de esa forma, nos parece, es restarle el carácter procesual que tuvo, el paso del mito al logos no es un paso, sino, un despertar.

14. Cfr., Muñoz Martínez, Rubén, Tratamiento ontológico del silencio en Heidegger, Fenix Editora, España, 2006, p. 14. 
Aristóteles, sin embargo, recupera el valor epistémico que la metáfora posee, dicho valor radica en que la metáfora trae a presencia algo que escapa de cualquier intento de aprehensión, "Y de esa manera opera el propio Aristóteles cuando sostiene que la metáfora hace saltar a la vista o poner ante los ojos (alguna cosa); en griego pro ommaton poien", ${ }^{15}$ la metáfora en ese "hacer saltar a la vista" funciona como una exhibición y exhibe aquello que no acontece empíricamente, y sólo así, ese objeto que no acontece en la experiencia puede ser objeto de conocimiento.

"La metáfora, en la medida en que logra "poner algo ante los ojos", produce un efecto análogo a lo que tiene lugar en cada momento de nuestra vida: en nuestro natural comportamiento con los entes, es común- y por eso no llama la atención-que ellos se nos den como se nos dan: haciéndosenos presente". ${ }^{16}$

La metáfora implica, así, una lejanía que se torna cercanía ya que esa realidad supraempírica por el hecho de no acontecer fenoménicamente es algo fuera de nuestra experiencia, es decir, es una lejanía que al ser nombrada metafóricamente se vuelve cercanía porque deviene presencialidad, y no sólo eso, podemos hablar también de una especie de trans-semanticalización, con esto nos referimos a que la significación de los términos que entran en juego en la metáfora padecen un cierto cambio de significado al verterse un término al otro, pasando así a significar otra cosa.

"Y esto es lo que ocurre exactamente en la metáfora: el término vuelve la cara, por así decirlo - una metáfora más-, a su significación original, se desentiende parcialmente de esta -no del todo- y opera traslaticiamente convirtiendo la expresión original en una nueva significación o dando lugar a ella; cambia para pasar a significar otra cosa". ${ }^{17}$

Lo fenoménico acontece en la cotidianidad del sujeto, lo suprasensible no, la metáfora se ubica entre estos dos campos de realidad, la conceptual y la inconceptualizable, volviéndola en cierta forma legible e intelegible, pero no a modo de comparación, sino diciendo "esto es aquello", ${ }^{18}$ la metáfora señala semejanzas, contribuyendo así a la ampliación del conocimiento. Dicha afirmación es problemática, debido, como se señaló anteriormente, a la confianza desmesurada en el concepto que ha acompañado a la filosofía, y que encuentra su punto álgido en Hegel y las diferentes áreas del conocimiento en general. Sin embargo, en el apartado siguiente trataremos de demostrar que el uso que Kant hace de las metáforas no es un uso ornamental ni estilístico ni meramente estético, sino que la metáfora se constituye en un elemento fundamental del desarrollo de su metafísica.

15. Neumann, Hardy. La metáfora en Aristóteles y su contribución a la comprensión. En: Byzantion Nea Hellás 31, Santiago de Chile, 2012. p. 51.

16. Ibid., p. 58

17. Ibid, p. 52

18. Cfr, ibid., p. 64 


\section{La metáfora como limitación (Schranken) y hablar-sugerente en el sistema kantiano}

Debido al posicionamiento del cual partimos para el desarrollo de este trabajo obviaremos referirnos a la dimensión estética o retórica de la metáfora para centrarnos, desde nuestra lectura, en el carácter fundante que la metáfora tiene en la metafísica kantiana. Comencemos por señalar que ésta se desarrolla de cara a aquella metafísica previa dogmática especulativa que niega cualquier posibilidad de conocimiento a partir de la experiencia, siendo esto una de las características más importantes de la nueva metafísica, “[...] la nueva metafísica exigirá la más estricta vinculación a un referente ontológico-empírico que participe en un sistema de conocimiento. Este compromiso convertirá el discurso metafísico en un metalenguaje de otro lenguaje, en un metaconocimiento de otro conocimiento". ${ }^{19}$

Si la metafísica, según Kant, para tener valor científico debe estar anclada en la experiencia (intuiciones), cómo queda la afirmación hecha a inicios de este trabajo de que la metafísica kantiana sería un intento de realizar el tránsito ${ }^{20}$ de lo empírico a lo supraempírico, cómo eso que escapa a la experiencia puede devenir tal (intuición), la respuesta a esta interrogante la podemos encontrar en la metáfora. En la KU, Kant desarrolla la metodología de cómo esas ideas o conceptos de razón pueden ser exhibidas (Darstellung) en la intuición (Anschauung). Dicha exhibición (Darstellung) al contrario de los conceptos del entendimiento se realizará de forma indirecta mediante símbolos, esta simbolización funcionará como una analogía y ésta se manifestara en la metáfora, la metáfora, en Kant, funciona como una analogía, y es precisamente esto lo que permite cierto nivel de acceso epistemológico a aquello sugerido por la metáfora, respondiendo así, al señalamiento que Kant hiciese en la KrV en cuanto a la necesidad de que ciertas ideas de razón fuesen exhibidas.

La metáfora se encuentra entre el juicio determinante y el juicio reflexionante y es este último con el cual se encuentra más estrechamente vinculada, "La capacidad de reflexión que posee el hombre le permite a este comprender que ciertas manifestaciones sensibles no se agotan en sí mismas sino que remiten o apuntan hacia contenidos racionales de una naturaleza más elevada". ${ }^{21}$ Para el desarrollo de este apartado nos centraremos principalmente en Kritk Der Urteillskraft (1790) nos interesa especialmente porque es donde Kant elabora claramente el papel que el símbolo tiene en el proceso del conocimiento y que más tarde en Welche sind die Wirklichen Fortschritte, die Methaphysik

19. Jaques, Jessica. La revolución copernicana de Kant: la fundación de una nueva metafísica relacional relativista. En: Themata, Revista de Filosofía, Número 34, 2005, p. 96.

20. Cfr., Caimi, Mario. Op. Cit., p. 9.

21. Charpenel, Eduardo. Pensar la moral desde la belleza : una lectura del parágrafo cincuenta y nueve en la Kritik Der Urteilskraft, en, “Tópicos 41", 20II/II/29, Universidad Panamericana, México D.F, p. 189. 
seit Leibnizens und Wolffs Zeiten in Deutschland gemacht hat? Será algo fundamental en su planteamiento metafísico, ya que será éste, el símbolo, el que posibilitará el paso de lo sensible a lo suprasensible, "Este fin último al que apunta toda la metafísica es fácil de descubrir, y puede, en este respecto, fundamentar una definición de ella: "es la ciencia de progresar mediante la razón, del conocimiento de lo sensible al de lo suprasensible",22 mientras que en la tercera crítica es donde Kant abre la posibilidad de, a través de la analogía, hablar de un conocimiento diferente que marcaría el acceso a lo suprasensible, a saber, el conocimiento simbólico.

En la KU, Kant nos dice:

"Toda hipotiposis (exposición, sujectio sub adspectum), como sensibilización, es doble: o esquemática, cuando a un concepto que el entendimiento comprende es dada a priori la intuición correspondiente, o simbólica, cuando bajo un concepto que sólo la razón puede pensar, y del cual ninguna intuición sensible adecuada puede darse, se pone una intuición en la cual sólo el proceder del juicio es análogo al que observa en el esquematismo, es decir, que concuerda con él sólo según la regla de ese proceder y no según la intuición misma; por lo tanto, sólo según la forma de la reflexión y no según el contenido". ${ }^{23}$

La hipotiposis es fundamentalmente un proceso, tal como lo dice Kant, un proceso, que es doble, por un lado puede ser esquemática cuando a los conceptos del entendimiento le es dado su respectivo correlato empírico y simbólico cuando éste es un correlato transempírico, ${ }^{24}$ de tal manera que los correlatos, es decir, intuiciones (Anschauung) son de naturaleza diferente. Sin embargo, La analogía (Analogie), que opera en la $K U$ a través del símbolo, no análoga objetos (Gegenstande), sino relaciones. Hemos señalado anteriormente con Aristóteles que la metáfora "hacer saltar a la vista" pero cuando ésta funciona como una analogía (Analogie) aunque si bien es cierto hace referencia en primer lugar a la vista no se refiere exclusivamente a ésta sino a cualquier forma en que el conocimiento se refiera a los objetos. La analogía (Analogie) se cifra en la KU bajo el símbolo y no bajo el signo, en este sentido, es importante diferenciar entre signo (Zeichen) y símbolo (Symbol), el signo para Kant no

22. Kant, Immanuel, Los progresos de la Metafísica; Traducido por Mario Caimi. Primera edición. Eudeba, Buenos Aires, 1989, p.260.

23. Kant, Immanuel, Critica del juicio, Alicante: Biblioteca virtual Miguel de Cervantes, 1999, pp.173-174. "Alle Hypotypose (Darstellung, subiectio sub adspectum) als Versinnlichung ist zwiefach: entweder schematish, da einnem Begriffe, den der Verstand faBt, die korrespondierende Anschauung angemessen sein kann, eine solche untergelegt wird, mit welcher das Verfahren der Urteilskraft demjeningen, was sie im Schematisieren beobachtet, bloB analogish ist a), d. $i$. mit ihm bloB der Regel dieses Verfahrens, nicht der Anschauung selbst, mitin bloB der Form der Reflexion, nicht dem Inhalte nach übereinkommt".

24. Véase., Pieper, Annemarie. Op.cit. Véase también, Maly, Sebastian, Kant über die symbolische Erkenntnis Gottes, De Gruyter, Berlin, 2012. 
posee relevancia epistemológica, su función más bien es la de comunicar representaciones conceptuales que pueden ser utilizadas para la comunicación intersubjetivas o para establecer relaciones con la imaginación o la memoria, ya que a través de ellos evocamos conceptos, los signos hacen llamados regresivos (zurück-zurufen), ${ }^{25}$ por lo que poseen meramente un carácter consensuado y por lo tanto arbitrario, por ello, según Kant, no producen conocimiento.

La analogía (Analogie), por el contrario, que opera a través del símbolo al traer a presencia un objeto transempirico, crea una intuición (Anschauung) que permite la exhibición de dicho “objeto" (Gegenstand), pero esta exhibición (Darstellung) no es de la misma naturaleza que la que se lleva a cabo en el esquematismo porque antes de que este momento suceda las ideas de razón están en una especie de privación, es decir, están privadas de la intuición (Anschauung) correspondiente, que permitiría llevar a cabo el conocimiento, de ahí que lo que el símbolo, es decir la metáfora, analoga no es el objeto, como ya se mencionó anteriormente, sino el proceso, pero un proceso fundado en la consecuencia que implica el decir, "esto es aquello" de la metáfora. El proceder del juicio reflexionante queda analogado al proceder del juicio determinante lo que significa que el símbolo es un análogo del esquematismo por lo que podríamos decir que éste funciona como una suerte de cuasi-esquema, ${ }^{26}$ en este sentido Kant señala:

"Cuando se opone el símbolo al modo de representación intuitivo, se hace de aquel vocablo un uso que, aunque admitido por los lógicos modernos, trastorna su sentido y lo falsea, pues el simbólico es sólo un modo del intuitivo. Este último puede, en efecto, dividirse en modo de representar esquemático y simbólico. Ambos son hipotiposis, es decir, exposiciones (exhibitiones), no meros caracterismas, es decir, designaciones de los conceptos por medio de notas sensibles que los acompañan, y que no encierran nada que pertenezca a la intuición del objeto, sino que sirven a aquellos según la ley de la asociación de la imaginación, por tanto, en intención subjetiva, de medio de reproducción; los tales son, o palabras, o signos visibles (algebraicos, y hasta mímicos), como meras expresiones para conceptos". ${ }^{27}$

\footnotetext{
25. Cfr., Las Heras, Manuel Vidal, Kant y el simbolismo, tesina para optar al grado de licenciado en Filosofía, Universidad de Chile, 2010, p. 17.

26. Cfr., Ibid. p. 27.

27. Immanuel, Kant, Critica del juicio, Op.cit., p. 174. "Est ist von den neueren Logikern zwar angenommener, aber sinnverkehrender, unrechter Gebraucht des Worts symbolich, wenn man es der intuitive Vorstellungsart entgegensetzt; den die symbolische ist nur eine Art der intuitive. Die letztere (die intuitive) kann nämlich in die schematische und in die symbolische Vorstellungsart eingeteilt warden. Beide sind Hypotipose, d. i. Darstellung (exhibitions); nicht bloBe Charakterismen, d.i. Bezeichnungen der Begriffe durch begleitende sinnliche Zeichen, die gar nichts zu der Anschauung des Objekts Gehöriges enthalten, sondern nur jenen nach dem Gesetze der Assoziation der Einbildungskraft, mithin in subjektiver Absicht, zum Mittel der Reproduktion dienen; dergleichen sind entweder Worte oder sichtbare (algebraische, selbst mimische) Zeichen, als bloBe Ausdrücke für Begriffe".
} 
El símbolo establece relaciones entre un concepto de razón y un objeto supraempirico, y el conocimiento surge precisamente en esa relación que el símbolo ha posibilitado lo que significa que no es que se aprehenda ese objeto suprasensible, sino que se aprehende la forma como acontece en relación con nuestro mundo, señalando al mismo tiempo a aquello desconocido, desconocido por no acontecer fenoménicamente, del que es símbolo, así el símbolo al mismo tiempo que exhibe (Darstellung) relaciones sugiere, es decir, señala, al objeto suprasensible.

El símbolo entonces posibilita el conocimiento de las realidades suprasensibles a partir de las relaciones que éstas tienen con intuiciones que encontramos en la naturaleza y en nuestra cotidianidad. El símbolo ${ }^{28}$ produce un conocimiento de origen simbólico (relacional) que es análogo al conocimiento producido por el esquematismo, una de las diferencias fundamentales entre ambos sería que el conocimiento que el símbolo produce es un conocimiento límite ${ }^{29}$, un conocimiento de frontera, debido a que su origen se encuentra precisamente en el límite (Grenzen) de lo empírico y lo supraempírico. La metafísica kantiana se ubica precisamente en este límite, constituyendo, según Kant, una cierta superación de él. Y es que Kant, más que entenderlo como límite (Grenzen), en sentido estricto, lo entiende como limitación (Schranken), limite implica un encierro, un claustro, mientras que limitación está más relacionado con ausencia de algo y no implica necesariamente un encierro, “Los límites (en seres extensos) presuponen siempre un espacio que se encuentra fuera de un cierto lugar determinado y lo encierra; las limitaciones no requieren esto, sino que son meras negaciones que afectan a una cantidad, en la medida en que no tiene integridad absoluta, ${ }^{30}$ en esta misma línea Mario Caimi señala que la razón está limitada, sí, pero no con límites, sino con limitaciones ${ }^{31}$. Kant nos dice, "En este caso no tendríamos que investigar la cosa suprasensible con respecto a cómo sea ella en sí, sino sólo con respecto a cómo tenemos que pensarla nosotros, y cómo tenemos que suponer es su naturaleza [...]". ${ }^{32}$ La cita anterior señala claramente la limitación (Schranken) que nuestra razón posee; el conocimiento que podamos obtener de aquello que supera lo fenoménico siempre será un conocimiento simbólico porque no nos es posible aprehender aquello que supera nuestra experiencia y cotidianidad, sin embargo, cierto acceso es posible, por ello, La metafísica es entonces un tránsito a partir de los límites (Grenzen) que el mismo Kant ha señalado en la $K r V$ con respecto al conocimiento, sin embargo, esa limitación (Schranken), señala Kant, no puede obstaculizar el tránsito, simbólico, a aquello que está más allá de la experiencia. Kant, para evitar caer en una suerte de dogmatismo señala que esa limitación (Schranken) no es de las cosas sino de la razón misma.

\footnotetext{
28. Debemos recordar que usamos símbolo y metáfora indistintamente.

29. Cfr., Caimi, Mario. Op. Cit., p. 25.

30. Cf., Kant, Immanuel. Prolegómenos a toda metafísica futura que haya de poder presentarse como ciencia, Ediciones Istmo, Madrid, 199, p. 255.

31. Cfr., ibidem.

32. Kant, Immanuel. Los progresos de la Metafísica, Op.cit., p. 296.
} 
Los limites (Grenzen) nos marcan la división de los planos, el fenoménico y el noumenico, pero este marcar división no implica que se trate de una separación total, porque hay cierta conexión, de no ser así, sería imposible que el símbolo nos permitiese cierto nivel de conocimiento de ese plano nouménico. ${ }^{33}$ Dicho esto es claro entonces que habitamos en ese lugar donde ambos planos, empírico y supraempírico, se rosan. Los correlatos supraemepíricos que el símbolo exhibe (Darstellung) apuntan, parafraseando a Kant, a esa otra orilla de ese mar infinito que es la metafísica. ${ }^{34}$ La metáfora es así ese sustrato que apunta al fondo indecible de la experiencia ${ }^{35}$ y al sólo apuntar no enclaustra eso que señala, sino que sólo lo sugiere, es imposible la aprehensión de los objetos suprasensibles, así que la única forma en que puede posibilitarse el acceso es a través del símbolo, es decir, la metáfora, pero la metáfora al decir "esto es aquello" 36 no lo hace de una forma determinante, sino que simplemente señala semejanzas. La metáfora así constituye un elemento fundamental del lenguaje filosófico, 'transferencias', que no se pueden reducir a la logicidad del concepto, ${ }^{37}$ ésta irrumpe en el momento en que el proceso de conocimiento basado en lo conceptual fracasa porque aquello de lo que quiere dar cuenta resulta inaprehensible y se resiste a ser encerrado en un concepto, al ser la metáfora un límite, que muestra la limitación de nuestra razón, no encierra, sino que sugiere eso que ha escapado a la actividad del logos, por ello, desde nuestra perspectiva, el símbolo sería un hablar-sugerente.

\section{Conclusiones}

Debemos señalar dos cosas: la primera, el propósito de este trabajo no ha sido realizar una descripción ni explicación de la hipotiposis simbólica, nos ha interesado más bien, señalar sólo aquellos elementos que ayudan a tener una idea de cómo ésta acontece y cómo ayuda al conocimiento simbólico. Nuestra pretensión ha sido, más bien, salirnos de la lectura usual que se ha hecho del sistema kantiano y poner nuestra atención en la propuesta de lectura de Mario Caimi -siendo esto lo otro que debemos señalar, lo que se ha realizado en este trabajo ha sido una aproximación a la propuesta de Caimi, no hemos pretendido agotar la temática sino mostrarla como un interés futuro de investigaciónpara quien, el sistema kantiano apuntaría a la elaboración de una metafísica, una metafísica definida a partir del símbolo en la medida que es éste el que nos permite habitar ese límite y al mismo tiempo, lograr la conexión entre lo sensible y lo suprasensible.

33. Cfr., Las Heras, Manuel Vidal. Op.cit, p. 52.

34. Cfr., Caimi, Mario, La metafisica de Kant, Op. cit., p. 20.

35. Cfr., De Murcia, Conesa Antonio. Crítica y Metáfora: en torno a la retórica del sistema kantiano,en, $\Delta a^{\prime} i \mu \omega v$. Revista de Filosofía, Murcia, 2004, № 33, p. 95.

36. Cfr., Neumann, Hardy. Op.cit., p. 64.

37. Cfr., Durán Guerra, Luis, Metáfora y mundo de la vida en Hans Blumenberg, en, Revista de filosofía Vol. 35, № 2, España, 2010, p. 114. 
El Símbolo, sobre todo en la obra póstuma Welche sind die Wirklichen Fortschritte, die Methaphysik seit Leibnizens und Wolffs Zeiten in Deutschland gemacht hat? ${ }^{38}$ ya no es un recurso meramente estético ni retórico, nos parece que en ésta y en la $K U$ el símbolo ya no puede seguirse comprendiendo de la misma forma que en los escritos kantianos anteriores, el símbolo adquiere connotaciones que, nos parece, apuntan a un nueva forma de conocimiento metafísico y es esto lo fundamental desde nuestra perspectiva.

"La metafísica es aquí solamente la idea de una ciencia, la idea de un sistema que se puede y se debe construir luego de la consumación de la crítica de la razón pura, para lo cual se dispone ahora de las herramientas de construcción y del plano: una totalidad que, como lógica pura, ni requiere ni admite añadido alguno y que debe ser siempre habitada y conservada en condiciones de habitabilidad, si es que no han de anidar en ella, haciéndola inhabitable para la razón, las arañas y los duendes de los bosques, que nunca dejarán de buscarse un lugar allí”.39

La metáfora ha sido considerada como un estado primigenio del desarrollo del pensamiento y el concepto ha sido comprendido como su evolución. Ante esto, y al uso kantiano de la metáfora, cabe preguntarse si el concepto en su momento representó un evolución de la metáfora no cabría preguntarse qué así como hubo una evolución ahora es necesario hablar de una involución, o será más bien que la metáfora ha sido el medio por el cual el ser humano ha pretendido dar cuenta y acceder a aquello que le resulta avasallante y que escapa de su tendencia "logoficadora".

Sin duda, aún hay mucho que investigar en este camino, y el sesgo conceptual constitutivo de la filosofía puede ser un obstáculo en la profundización de esta nueva lectura interpretativa que recién comienza a abrirse, sin embargo, la necesidad de acercarnos a nuevas formas de conocimiento que no tienen a la base esa conciencia conceptualizadora, y por lo tanto desgarrada ${ }^{40}$ se impone como un imperativo para continuar el avance hacia "nuevas" formas de habérnoslas con el mundo.

38. Mario Caimi en su estudio preliminar a Welche sind die Wirklichen Fortschritte, die Methaphysik seit Leibnizens und Wolffs Zeiten in Deutschland gemacht hat? Señala que esta obra póstuma pudo haber sido escrita alrededor de 1793.

39. Kant, Immanuel. Los progresos de la Metafísica; Traducido por Mario Caimi. Primera edición. Eudeba, Buenos Aires, 1989. 310.

40. Véase, Zambrano, María. Filosofía y poesía, Fondo de cultura económica, México, 1993. 


\section{Bibliografía}

\section{a) Textos-Fuentes. Ediciones. Traducciones}

Kant, Immanuel, Kritik der Urteilskraft, Herausgegeben von Karl Vorländer, Verlag von Felix Meiner in Hamburg.

Kant, Immanuel, Critica del juicio, (1999), Alicante: Biblioteca virtual Miguel de cervantes Kant, Immanuel, (1989), Los Progresos de la Metafísica, Traducido del alemán por Mario Caimi, $1^{\text {a }}$ edición, Eudeba, Buenos Aires.

Kant, Immanuel, (2009), Crítica de la Razón Pura, Traducción, estudio preliminar y notas por Mario Caimi, Edición bilingüe, Fondo de Cultura Económica, México D.F.

Kant, Immanuel, (1999), Prolegomenos a toda Metafísica Futura que haya de poder presentarse como Ciencia, Edición, traducción directa del alemán comentarios y notas por Mario Caimi, Epílogo de Norbert Hinske, Edición bilingüe, Ediciones Istmo, Madrid.

\section{b) Complementaria}

Heidegger, Martin, (2001), Sein und Zeit, Max Niemeyer Verlag, Tübingen.

Heidegger, Martin, (2003), Ser y Tiempo, Traducción, prólogo y notas por Jorge Eduardo Rivera, Ed. Trotta, Madrid.

Muñoz Martínez, Rúben, (2006), Tratamiento ontológico del silencio en Heidegger, Fenix Editora, España.

Corvez, Maurice, (1970), La Filosofía de Heidegger, Fondo de Cultura Económica, México, D.F.

Blumenberg, Hans, (2011), Descripción del Ser Humano, Traducción de Griselda Mársico con la colaboración de Uwe Schoor, Edición póstuma, Fondo de Cultura Económica, Buenos Aires.

Blumenberg Hans, (2004), El Mito y el Concepto de Realidad, Traducción de Carlota Rubies, Herder Editorial, Barcelona.

Blumenberg, Hans, Paradigmas para una metaforología, Traducción de Jorge Pérez de Tudela, Trotta, Madrid, 2003

Caimi, Mario Pedro Miguel, (1989), La Metafísica de Kant, Eudeba 1989, $1^{\text {a }}$ Edición Buenos Aires.

Neumann, Hardy, (2012), “La Metáfora en Aristóteles y su contribución a la Comprensión”, en: Byzantion Nea Hellás 31, 2012: 47-68.

Durán Guerra, Luis, (2010), “Metáfora y Mundo de la Vida en Hans Blumenberg”, en: Revista de Filosofía $\mathrm{N}^{\circ} 35,105-128$

Fragio, Alberto, (2012), “Hans Blumenberg: Las dificultades de la llustración a través de sus metáforas", en: Anales del Seminario de Historia de Filosofía, Vol. $29, N^{\circ} 2$.

Carrapiso Araujo, Manuel, (1997), “Prolegómenos a una Crítica de la Razón Poética”, en: Anuario de Estudios Filológicos, Vol 20, 1997: 41-60.

Rivera García, Antonio, (2010), “Hans Blumenberg: mito, metáfora absoluta y filosofía política”, en: Ingenium, Revista de Historia del Pensamiento Moderno, $\mathrm{N}^{\circ} 4$, julio-diciembre 2010: 145-165. 
Jaques, Jèssica, (2005), “La 'Revolución Copernicana de Kant': la Fundación de una Metafísica Relacional Relativista”, en: Thémata $\mathrm{N}^{\circ} 34$.

Ros Velasco, Josefa, (2010), “La Recepción de la Metáforología de Hans Blumenberg”, en: Res Pública, Revista de Filosofía Política N2 24 2010: 225-236.

Charpanel Elorduy, Eduardo, (2011), "Pensar la Moral desde la Belleza: una lectura del parágrafo cincuenta y nueve de la Kritik der Urteilskraft”, en: Tópicos 41, 2011: 183-221.

De Murcia Conesa, Antonio, (2004), “Critica y Metáfora: en torno a la retórica del sistema kantiano", en $\Delta \alpha^{\prime}(\mu \omega v$, Revista de Filosofía, Murcia № 33.

Las Heras, Manuel Vidal, (2010), Kant y el Sómbolimos, Tesina de Grado, Universidad de Chile, Santiago de Chile.

Pieper, Annemarie, (1996), "Kant und die Methode der Analogie", en, Kant in der Diskussion der Moderne, hgr, Von G. Schönrich und Yasushi Kato, Suhrkamp, F.a.M.

Dominguez Miranda, Manuel, (1993), “Aproximaciones al concepto de praxis en Ignacio Elalcuría”, en, Universitas Philosophica 21, Bogotá.

Dirán Guerra, Luis, (2010) “Metáfora y mundo de la vida en Hans Blumenberg”, en, Revista de filosofía Vol. 35, № 2. España. 